\title{
Archetypal Symbolism in the Recovery Process from Natural Disaster: Sandplay Therapy of Nepal Earthquake Adolescent Survivors*
}

\author{
Mikyung Jang**
}

\begin{abstract}
$<$ Abstract $>$
The purpose of this study was to analyze the process of psychological recovery following earthquakes as well as the archetypal symbolism in the process of sandplay therapy. The study participants were 12 adolescents who had resided for 16 months in a temporary camp for those displaced after the earthquakes in Nepal in 2015. The participants typically created scenes of archetypal invasion (Attacks by snakes, beasts, aliens, monsters and unidentified assailants), earthquakes or the aftermath of earthquakes (Earthquake, destruction of buildings, volcanic explosions), Helping Forces (Emergence of heroes, police, father or outsiders/Soldiers, weapons, and fighting scenes between soldiers and animals/monsters, and bad people Gods), and reconstruction of homes (Construction of a new and good nation), Recovery of Order (Division, well-compartmented strong houses/Peaceful nature, family and home). The religious and cultural in influences on the participants were reflected in their sandpictures and comments that the earthquake was caused by a divine being. Yet at the same time they expressed in archetypal symbols their ability to recover with the help of this divine presence.
\end{abstract}

Keywords : natural disaster, earthquake, sandplay therapy, adolescents, archetype

* This paper was funded by Namseoul Univiersity in 2017.

** Professor, Department of Child Welfare at Namseoul University (jangmiky@nsu.ac.kr) 
Journal of Symbols \& Sandplay Therapy, Vol.8 No.2.

\section{I . Introduction}

In April and May 2015 two earthquakes with magnitudes of 7.8 and 6.7 struck Nepal, killing almost 9,000 people and destroying or damaging most old brick buildings in the affected regions. Natural disasters such as these have a negative effect on the survivors' mental health, including PTSD, depression, anxiety, and somatic symptoms as well as on physical health. However, different factors can act as buffers and moderate these negative effects.

After a disaster like an earthquake, individuals can utilize coping strategies to gain control over their stressful emotions and the problems in their environment (Lazarus \& Folkman, 1984; Smith et al., 2014). One such coping strategy is seeking religious consolation (Lazarus, Jimerson, \& Brock, 2003). Since natural disasters can occur without warning and may be extremely destructive this may explain why people seek religious comfort for anxiety in addition to support from family and community. And indeed, research does suggest that religion is an effective coping strategy (Salloum \& Lewis, 2010; Smith et al., 2014).

When a natural disaster strikes, people often turn to archetypal images of their gods. Recollecting images of a god can help to maintain mental balance. In particular, it is a constellation of the archetype of the self of the collective unconscious (Jung, 1984/2007; Kim, 2014). Thus, when the constellated unconscious and archetypal energy are the result of a natural disaster, they are experienced as god. To prevent the ego function from being overwhelmed by archetypal energy, people need images of god. Jung noted that there are countless magical rites with the sole aim of protecting the individuals from the unexpected and dangerous overflow of the unconscious (Jung, 1984/2007, pp. 40-41). Those who directly experience or witness the loss of life and property in an earthquake will likely conduct such rites by utilizing the images of their gods through different symbolic means to seek the gods' mercy.

Hinduism and Buddhism are the two major religions practiced in Nepal. Approximately $75 \%$ percent of the Nepalese people are Hindu and the remainder of the population is almost all Buddhist. In Nepalese Hinduism, there are twelve gods and each god serves a different function. Nepalese culture may be characterized by its strong ties with religion. There are many small temples in natural settings in the country, including temples 
near rivers, mountains, and entrances to towns. Many people also have a small shrine in their home. Due to the influence of their religions, the Nepalese people are not culturally accustomed to expressing emotions, especially negative ones. The reason seems to rest with the religious concepts of Buddhism and Hinduism. The key concepts of Hinduism influenced by Buddhism are karma and samsara (Han, 2010).

The term karma is derived from the Sanskrit word kriya, meaning "to do, make, perform, accomplish, cause, effect, prepare, undertake." Individuals may feel either pleased or distressed by the power of karma. As a result of new karma, a soul may fail to escape its life and live on through countless, repetitive incarnations. Repeating a life that is endlessly entangled with karma is called samsara.

According to these religions, Hinduism and Buddhism, action with desire makes us subject to samsara. Therefore, one may reach completeness by giving up desire, controlling the mind and body, discarding all possessiveness, and only performing the actions that are necessary for maintaining life. Hence, feelings of anger and resentment about a difficult situation and jealousy toward those who do not suffer are taboo in Nepal (Cho, 2004). Religion is also a way for the Nepalese people to contain and heal the negative emotions that they experience after an earthquake, such as anxiety, depression, and resentment. They believe that they may be rewarded in the afterlife for choosing to pray to the gods instead of entertaining feelings of anger, resentment, and desperation.

For Nepalese people accustomed to this dominant religious culture, sandplay therapy can provide a means to symbolically express their emotions. Sandplay is influenced in particular by Buddhism, which ultimately seeks the integration of spirit and matter through the body by embodying the spirit and spiritualizing the body (Markell, 2002). Furthermore, it is based on analytical psychology, which emphasizes the importance of the archetypal psyche, especially the self archetype, which is the unconscious, spiritual, religious, transcendent, and essential part of the human psyche that influences the individual's consciousness and life (Markell, 2002).

The techniques of sandplay therapy are indebted to the work of Jungian therapist Dora Kalff (2003), who drew inspiration from the use of sand and miniatures in child therapy by psychotherapist Margaret Lowenfeld. During sandplay therapy, an individual is asked to 
Journal of Symbols \& Sandplay Therapy, Vol.8 No.2.

select figurines of food, houses, animals, buildings, humans, religious entities, means of transportation, and etc.. They are then asked to place them in a tray half filled with sand and to create scenes and stories (Steinhardt, 2000). The inside of the sandtray is blue and can symbolize the sky or the ocean. Through playing in the sandtray, individuals may express traumas, ideal situations, specific problems, and different kinds of conscious and unconscious emotions through activities like digging, burying, patting, and hiding.

Actions and other nonverbal expressions of emotion can actually have a more immediate effect than verbal expressions (Cook et al., 2005; Lacroix et al., 2007; Malchiodi, 2003). Using one's hands facilitates the expression of trauma that was experienced by the body (Brody, 1997). These nonverbal expressions about emotions and actions can have more immediate effects on healing and can be activated through intervention using sensory touch (Steele, 2006).

In their book Trauma, Culture and Metaphor: Pathways of Transformation and Integration, Wilson and Lindy (2013) noted that the abyss of trauma was a shattering moment that changed one's personality and a nurturing guide was necessary in order to overcome such an experience. From the perspective of heroic mythology, they compared a hero's passing over a threshold to the survivor's process of recovering from their trauma. They presented the process of reintegration that survivors go through in order to return to their ordinary life, and furthermore observed that in terms of a nurturing guide's role and quality, survivors required different responses in each stage for recovery from a trauma.

Wilson and Lindy mentioned healing functions by symbols in terms of linguistic symbols, although they are not symbols like figures: "These culturally-rooted attitudes create identifiable characteristics of the psychic-socio-emotional space of the encounter with the survivor. Metaphor as 'a figure of speech that suggests a likeness by speaking of one thing as if it were another (Lakoff \& Johnson, 1980)'." According to these authors, it is important to learn to 'Talk the Trauma-Specific Talk' through symbols (although they are linguistic symbols in their book). The trauma-specific metaphor theme is mapping their clinical paths. Trauma survivors comprehended the trauma they underwent and the process they went through when they were given an opportunity to express image symbols. 
Therefore, the aim of the current study was to provide the adolescent survivors of the Nepal earthquake with an opportunity to express their experience in a symbolic way. We have also endeavored to interpret their symbolism related to the earthquake experience and the recovery process in sandplay therapy.

\section{Study Method}

\section{1) Participants}

Sandplay therapy was provided to 12 adolescents who had resided for 16 months in a temporary camp for those displaced after the earthquakes in Nepal in 2015. They had experienced two large earthquakes along with several aftershocks. Every participant had lost their house and some family members, and in some cases had been injured themselves. Twenty-four adolescents aged between 14 and 17 were selected, and they were equally assigned to an experimental group and a control group. Both groups were six males and six females. Before the first session, the participants and their guardians were informed about how research and filming would be performed, and written consent was obtained from them. The volunteering adolescents were recruited among adolescents who obtained 19 points or higher in child report of posttraumatic symptoms and 16 points or higher in parent report of posttraumatic symptoms among Nepalese adolescent earthquake survivors who had participated in the project and conducted sandplay to them and measured its effects.

The location where the program was implemented was in a building of a tent village temporarily built by UNICEF at the time of the earliest earthquake. A total of eight sessions of sandplay therapy including an intake session was conducted on 12 members in the experimental group, and after the intervention in the experimental group was completed, the same sandplay therapy on the control group of 12 participants was carried out. Although group sandplay therapy was not consistent with the direction of Dora Kalffs sandplay therapy, sandplay therapy in a small group was inevitable because time and therapists were not enough to do long intervention. Two scales were used to do the pre-test and the post-test. 
Journal of Symbols \& Sandplay Therapy, Vol.8 No.2.

\section{2) Ethical Consideration}

To ensure ethical research practice, the participants were informed of the purpose of the study, that confidentiality of their identity and data would be maintained, and that they could withdraw from the study at any time. Written consent to participate was obtained from each individual. All names in this article are pseudonyms.

\section{Procedure}

For the psychological health of earthquake survivors in the Kathmandu area of Nepal, sandplay therapy was provided in a temporary building that served as UNICEF's office after the earthquake. The recruitment of participants was done through the use of flags, flyers, and local interpreters. The sandplay therapy was conducted in a 90-minute group session on six occasions over 14 days.

Dora Kalffs approach was used - a non-directive approach to provide free and protected space (Kalff, 2003). In addition, to ensure the validity of the qualitative analysis, two sandplay therapists participated in the sandplay therapy analysis consultation with two more therapists who submitted written consent about their private content. These two therapists have been working together and practicing for more than seven years in sandplay therapy.

\section{Data Analysis}

To analyze the scenes of the whole sandpictures as well as the common verbal contents of the clients, we used the amplification method from analytical psychology. The amplification method was originally proposed by Jung, and it is an association method based on the comparative study of mythology, religion and fairy tales, used in the interpretation of symbolic images (Sharp, 1991). In other words, this enables us to investigate the symbols used by clients to represent some aspect of the psyche, including the archetypal aspect of the collective unconscious, while collecting their reminiscences of the specific symbol and the situation at hand (Jung, 1993). The amplification method is useful when dealing with some obscure experience by setting it in a psychological context where it may be understood (Jung, 1993). 


\section{ПI. Results}

\section{Archetypal Invasion}

\section{1) Attacks by snakes, dinosaurs, dragons, monsters, and aliens}

Natural disasters, abuse, domestic violence, severe stress, and anger tend to be symbolized as attacks by snakes, dinosaurs, and monsters in adults' sandpictures as well as those of children and adolescents. Unsurprisingly, therefore, not only the sandpictures of Nepalese children but also those of Korean children living in areas where earthquakes had struck all contained scenes of attacks by snakes, dinosaurs, beasts, monsters, and aliens (Jang, unpublished, 2017). The snakes were particularly interesting because many people reported that they had seen snakes immediately before the Nepal earthquakes.

The process of balancing one's mind in order to face a threat tends to find expression in the form of animal symbols that will appear in dreams or symbolic works. Such symbols represent instincts. Jung cited dreams about snakes as an example. Snakes are the

Table 1. Themes and Contents of the Nepal Earthquake Adolescent Survivors

\begin{tabular}{cc}
\hline Themes & Contents \\
\hline Archetypal Invasion & Attacks by snakes, beasts, aliens, and unidentified assailants \\
\hline Earthquakes or scenes after earthquakes & Earthquake, destruction of buildings, volcanic explosions \\
\hline Helping Forces & Emergence of heroes, police, father \\
& or outsiders \\
& Soldiers, weapons, and fighting \\
scenes between soldiers and animals, & monsters, and bad people \\
Construction & Gods \\
\hline Recovery of Order & Construction of a new and good nation/Recovery \\
& Division, \\
& Houses \\
\hline & Peaceful nature, family and home \\
\hline
\end{tabular}


Journal of Symbols \& Sandplay Therapy, Vol.8 No.2.

representation of the world of instincts and in particular a process full of vitality that may be psychologically approached on a minimal level. Dreams about snakes refer to the mismatch between conscious attitudes of the mind and instinct, and snakes are the personification of threatening aspects of conflicts (Jung, 1990). In particular, snake figures appeared in the sandpictures of Nepalese participants much more frequently than those of Korean participants (Jang, unpublisehd, 2017). It can be easily understood in a Nepalese context considering the fact that one of the symbols of Shiva, who is the Hindu god of creation, destruction, and reconstruction, is a snake.

We can also think about the phenomenon from a neurobiological perspective. The human brain classifies, integrates, analyzes, stores, and responds to stimuli that it receives (Marteau et al., 2012; Perry 2006). The stimuli that are registered in our brain go through primary somatosensory processing in the low dimensional domain below our level of consciousness. Nonetheless, stimuli that are novel, important, or threatening are transmitted to the high dimensional cortex center for higher processing (Perry, 2008; Sara \& Bouret, 2012). Changes originating from newness, chaos, or threats block the cortex control network related to the conscious and intentional control of anxiety, hunger, thirst, wrath and other "primitive" emotions. In order to prevent being overwhelmed by such primitive emotions, our brain tries to operate the control networks as much as it can.

The sandpicture process symbolized by invasions of snakes, dinosaurs, beasts, monsters, and aliens is a symbol by which the body and the unconscious work to consciously and intentionally control the stimuli of earthquakes that trigger emotions of unexplainable and overwhelming anxiety. Therefore, the fact that earthquakes were symbolized by animals like dragons, snakes, and dinosaurs that represent the primitive and archetypal emotion of fear is valid from a neurobiological perspective.

What is interesting is that boys had a greater tendency for such expressions than girls. The reasons why girls made such expressions less than boys may be because 1) girls were educated that such play by girls is not socially desirable and 2) girls may possibly express it with different symbols. In regards to the first reason, boys tend to express the principle of power such as fighting or defense while girls have a stronger tendency to make compensation for their anxiety with caring and nature. 


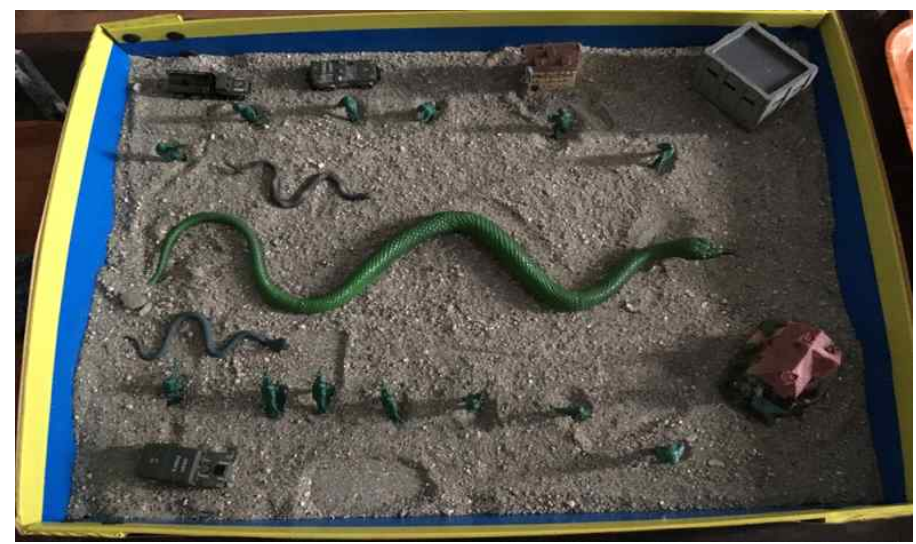

Figure 1. Male, 17 years old, $3^{\text {rd }}$ session

In this sandpicture the building at the rear right of the tray has been cracked by the earthquake. A large snake has come in from the jungle. Pointing at the cracked building, the client said that a family had used to live there but now it was very old and damaged. People were hiding because they were afraid of the large snake. Soldiers were attempting to protect them. A man holding a telescope is examining those who are running away, not those who are hiding.

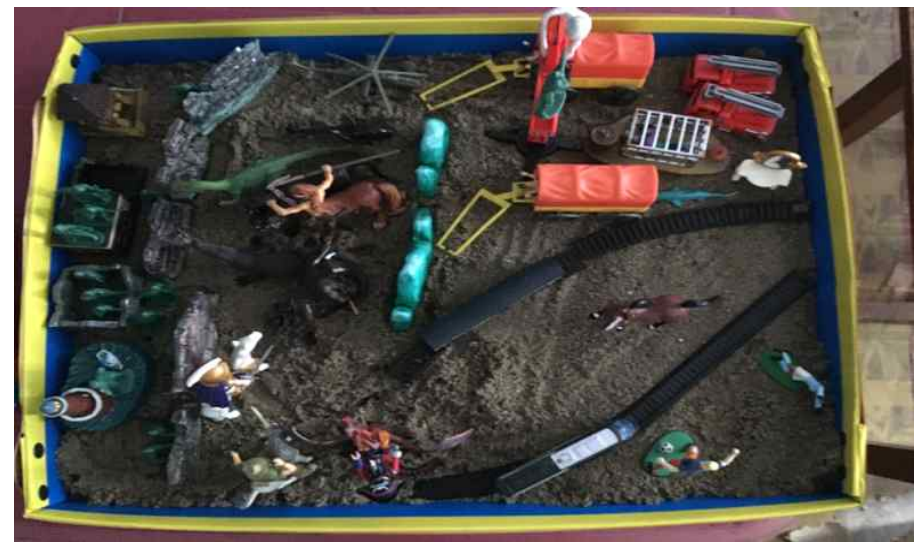

Figure 2. Male, 14 years old, $1^{\text {st }}$ session

The monstrous three-headed dog, Cerberus has a scary face and animals are invading from the left side to the right side of the tray. 
Journal of Symbols \& Sandplay Therapy, Vol.8 No.2.

\section{Earthquakes or scenes after earthquakes}

1) Earthquake, destruction of buildings, volcanic explosions

As mentioned earlier, psychological and physical health problems arise from external stresses and internal readiness conditions resulting from natural disasters (Rhi, 2012). Internal readiness conditions refer to the weakening of ego-consciousness triggered by personal traumas, lack of continuity of ego-consciousness, and dangerous emotional complexes within the unconscious threatening the consciousness. Psychological damage triggered by natural disasters like an earthquake may be aggravated by an individual's existing personal traumas, triggering further psychological and physical health problems.

The clients' sandpictures depicted the result of earthquakes: a nation thrown into chaos, destruction of buildings and villages, and death of people, with the earthquakes expressed as a volcanic explosion or attacks by animals, monsters, and aliens. Another motif was sand that caused death if someone ate it. The clients' expression "sand that kills the eater" was intriguing. They had thought of the Earth as giving and sustaining life, but the earthquake shocked them, and they subsequently seem to have symbolized the shaking and cracking earth as "the sand that kills the eater".

What is interesting is that while some children directly created earthquake scenes, others expressed them indirectly. Kawai (2015) has expressed the view that it is healthier to express earthquake experiences with a "small story" of difficulty in ordinary life rather than a "big story" of actual earthquake scenes in the sandtray. However, there should be a point in time when individual experiences about earthquakes themselves are directly expressed, whether they are direct expressions about the earthquakes or through symbols such as dinosaurs, snakes or aliens. The timing of this work may vary according to an individual's ego strength.

It is intriguing that this client connected an earthquake to a volcano. He explained that a volcano exploded and the people ran away. The animals moved to another place because they lost their homes. It seems that there will be a safe place for them if they go to the right side of the tray. 


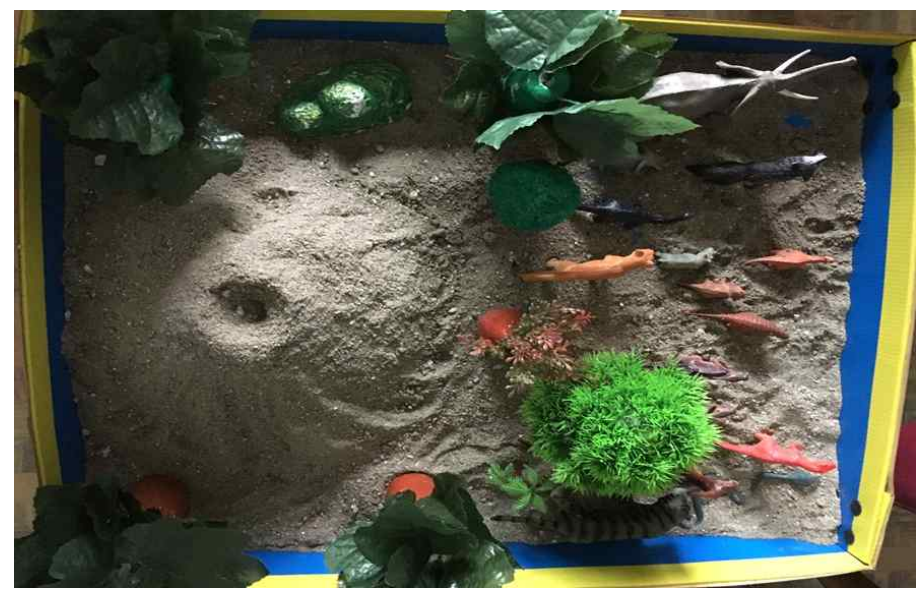

Figure 3. Male, 17 years old, $5^{\text {th }}$ session

\section{Helping forces}

Helping forces emerge in the chaos and they may be classified into a few types.

\section{1) Emergence of heroes, police, father or outsiders}

Heroes like superheroes, police, a powerful father, or outsiders such as foreigners came to help people in the devastated places. They helped those in crisis or fought against those who had caused it.

2) Soldiers, weapons, and fighting scenes between soldiers and animals, monsters, and bad people

Scenes where soldiers fought against an enormous force appeared from time to time. What was interesting was that airplanes, spaceships, and rockets also emerged as weapons. These were aimed at keeping distance from the shaking and collapsing earth. Also, scenes where such weapons were useless emerged, probably because aftershocks still continued and the clients thought they could not get away. In many cases the clients created scenes where soldiers or policemen did not look useful, perhaps highlighting the perceived ineffectiveness of these forces against the earthquake.

A war is taking place in this sandpicture against invading aliens from another world. 


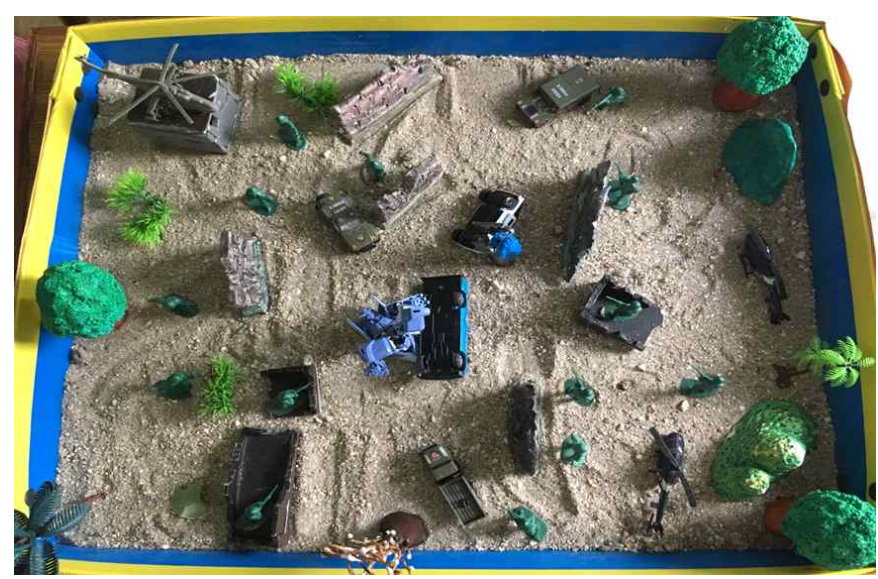

Figure 4. Male, 17 years old, $5^{\text {th }}$ session

There are ruined buildings and overturned cars. Soldiers are fighting in order to protect the Earth. Although they are frightened, they are fighting hard. Ultimately, the aliens retreated to their own world and the humans said that they would rebuild.

\section{3) Gods}

Almost without exception, the sandpictures of Nepalese survivors contained god figures. In Hinduism, gods wield sovereign power over all existence and therefore, humans have no right to dominate other creatures. Rather, humans are asked to obey the divine in Nature and live a life harmonious with Nature. The ancient people of India did not create Hinduism out of mere intellectual curiosity, but rather from a religious craving for an eternal existence beyond a finite and painful physical world that is changing constantly. Therefore, natural disasters like earthquakes may be experienced as something archetypal and divine.

Natural disasters and the resulting constellated unconscious archetypal energy are experienced as gods, and humans need divine images in order to prevent archetypal energy the unconscious constellation of the self-archetype (Jung, 1984/2007; Kim, 2014) - from flooding the ego function. Jung noted that there are countless magical rites conducted with only one purpose of defending oneself from unexpected dangerous flooding of the unconscious (Jung, 1984/2007).

For example, in traditional Korean times, when there was an omen of infectious 
diseases or unfortunate events - in other words, an omen of a god's descent - the people performed ancestral rites and mask dances in order to appease the god (Jang, 2015). Such rites to the god were performed because of the perception that the god gave life to humans and at the same time caused natural disasters such as earthquakes. Minimizing damage from the invincible god is to strengthen ego-consciousness. However, as mentioned earlier, existing traumas or the resulting personal complexes may disturb efforts to minimize damage to one's ego by archetypal energy.

Somatic symptoms, one of the typical symptoms of trauma, might appear trivial compared to earthquakes but when the ego's ability to endure the impact of earthquakes is weak; the body absorbs and expresses the impact instead of the ego. Therefore, the absence of expressions of earthquakes in psychotherapeutic settings such as sandplay therapy does not necessarily rule out any direct association with earthquakes. In other words, one should not assume that earthquake victims dealing with relationships or environments unrelated to earthquakes in their sandpictures are not expressing earthquakes.

That humans have created many rites to console gods and not incur their wrath is a kind of initiation (Rhi, 2012). Humans praise the same nature that has brought terrible natural disasters. Kawai, who applied sandplay therapy to those affected by tsunami, noted that humans had two emotions of fascination and fear toward nature (2015). When a natural disaster occurs, humans are afraid of the power of nature behind it. Indeed, the Japanese are said to have built hundreds of Shinto shrines on the seashore. At the same time, humans are attracted by the power of nature that provides abundant resources for them and they construct temples to acknowledge this.

The people of Nepal, which is a landlocked country with no ocean, have created temples in every village and individual homes as well as natural places. Prayer is an important part of their culture, whether during solar terms or when an individual has a problem or major life event such as marriage or the birth of a child. The reason is probably because Nepal spans the Himalayas, the highest mountain range in the world. This country has always witnessed the power of Nature and therefore its people know better than anyone else that Nature is where the gods dwell. 
Journal of Symbols \& Sandplay Therapy, Vol.8 No.2.

In many cases, Nepalese earthquake survivors created scenes of peaceful Nature in their sandtrays. These scenes comprised mostly of livestock and plants. Scenes where humans and animals such as cows, a sacred animal for Hindus, lived together in Nature frequently appeared. They expressed the survivors' hope that Nature would return to a peaceful state again and was also an unconscious symbolic expression of the hope that their anxiety and stress would dissipate.

The degree to which parents have become freed from negative emotions may determine their children's problems. In reality, parents or school teachers of children affected by earthquakes reported their reduced attention and concentration, increased separation anxiety from their parents, problems with their sleep or food intake, and problems of nightmares and nail biting.

The varying frequency of expressing god images may also be considered from different perspectives. Korean (Jang, unpublished, 2017) and Japanese children (Kawai, 2015) both included gods in their sandpictures, but the frequency was less than Nepalese children. In particular, in Korean children's sandplay, there were largely saviors from animated TV series and superhero movies. The reason is probably because unlike Korean culture where religious practices are separated from ordinary life, integration of life and religion has formed in Nepal. Omniscient and omnipotent figures from TV and movies are the savior images replacing gods in a culture where gods are disappearing.

Below, on the left side of the sandtray, there are houses and temples destroyed by

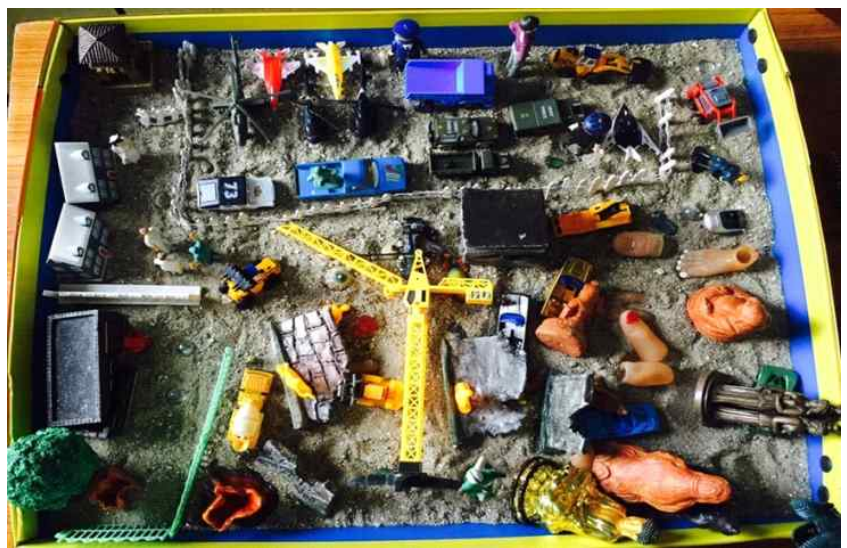

Figure 5. Male, 14 years old, $4^{\text {th }}$ session 


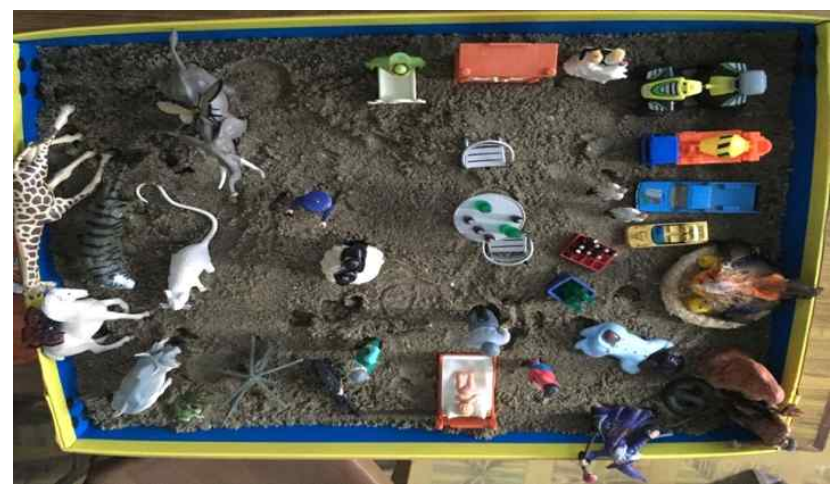

Figure 6. Male, 16 years old, $2^{\text {nd }}$ session

earthquakes and on the right side there are god statues. Many people died or were injured and the figures of eyes, feet, and fingers represent the injured. This client liked the airport and said that foreigners were arriving there to help the Nepalese people. The baby died in the earthquake because its parents only cared about themselves and so they abandoned it and ran away.

\section{Construction}

\section{1) Construction of a new and good nation}

Recovering was beginning in the reconstruction of a village or house. Scenes of people trying to keep order emerged as anxiety about the aftershocks subsided. In scenes where there

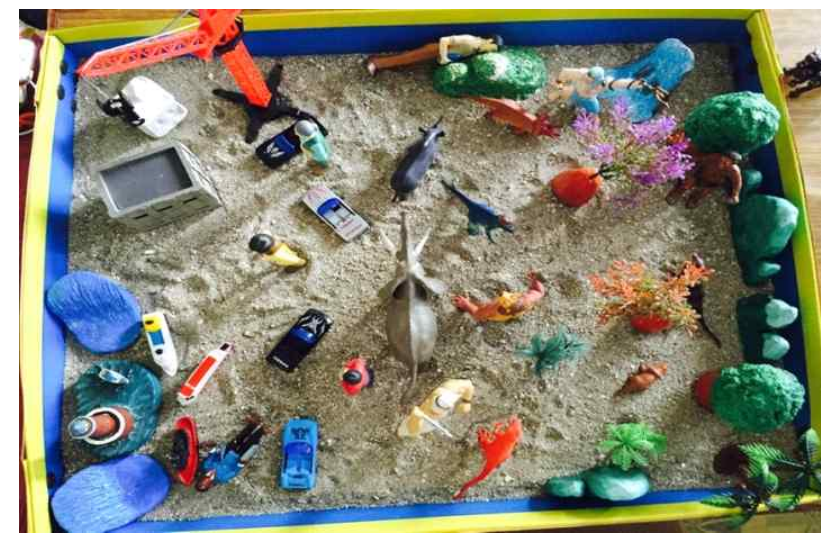

Figure 7. Male, 17 years old, $4^{\text {th }}$ session 
Journal of Symbols \& Sandplay Therapy, Vol.8 No.2.

was no fighting with monsters or dinosaurs, but rather the reconstruction of buildings that had been damaged or destroyed, the theme of order emerged.

\section{Recovery of Order}

\section{1) Division, well-compartmented strong houses}

Figures like fences, which symbolize order and division, were frequently used, and indeed well-ordered sandpictures were frequently created. Anxiety over earthquakes that may occur at any time, chaotic residential environment, economic difficulties, and an unpredictable future were expressed as compartmentalized fences, a neat house, well-constructed building or an automobile, the latter symbolizing wealth. Given that the psyche operates in a compensatory manner, it is natural that order is emphasized in the sandpictures of those who had suffered from earthquakes.

Nonetheless, whether such order means something was psychologically accomplished or something should be achieved in the future may differ according to the degree of recovery and the effects of earthquakes on psychological health. Emphasis on order in early sessions may signify the possibility of severe chaos still existing in the client's mind as well as the compensatory efforts and efforts of self-consciousness intending to control them.

Most buildings that collapsed due to earthquakes in Nepal had been built a long time

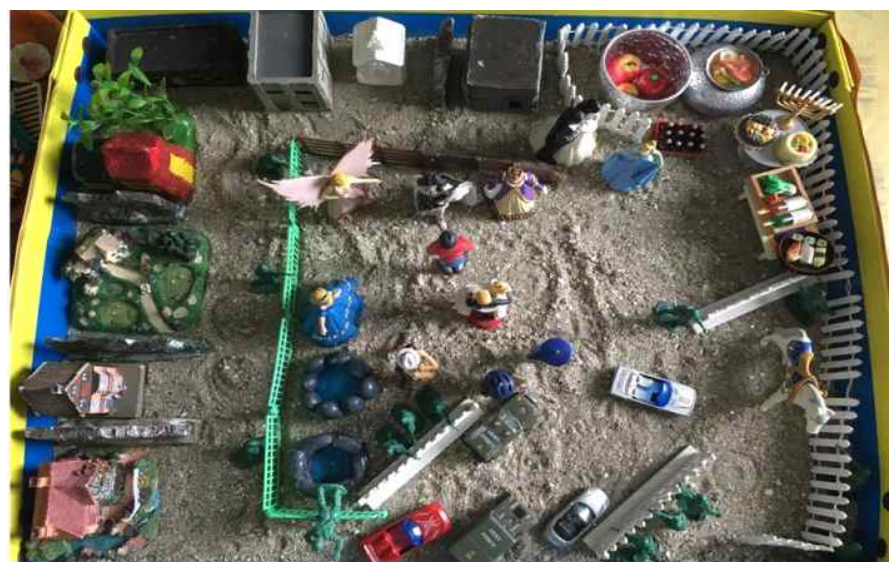

Figure 8. Male, 14 years old, $5^{\text {th }}$ session 
ago or were made of bricks rather than concrete. Therefore, those people whose homes were lost expressed the hope of owning a safe, strong house in the future. A house symbolizes personality (De Vries \& De Vries, 2004). It also symbolizes defense against collapse or weakening of the self structure by archetypal accidents. Therefore, a safe, strong house may be an expression of compensatory function, that is, the hope that the personality symbolized by the house would not be overwhelmed by psychological and environmental difficulties such as natural disasters.

Located on the left side of this sandtray is a house where a king lives. At the center there is the king. It is the birthday of the princess and therefore all have gathered to celebrate it.

\section{2) Peaceful Nature, peaceful home}

A caste system exists in Nepal, as in India, and while discrimination on the basis of caste was made illegal in 1962, and later reaffirmed in Nepal's 1990 constitution, it severely limits the career options available to the lower castes. Poor women, in particular, are greatly disadvantaged by this system. Those affected by the earthquake may well have thought they could do nothing but express religious hopes, given the understandable belief that higher caste men were in charge of the disaster relief operations and probably showing partiality in dispensing aid.

A lack of faith in the efficacy of the authorities to manage the country as well as in their own ability to resolve problems has led many Nepalese women to believe only outsiders can help them. Many Nepalese people cannot find jobs in their own country, so they leave to work abroad, thereby reinforcing this perception among the women.

Many female adolescents mentioned that their sandplay sessions were the first time they had talked openly about their future dreams. Due to the culture of Nepal, where it is taboo for women to express negativity and financial independence is relatively difficult to achieve compared to men, they seem to have a tendency to be protected by their parents or husbands. When a natural disaster like an earthquake takes place, homes, the only base for women, may be destroyed, or they face difficulties. In particular, the lower their class, the 
Journal of Symbols \& Sandplay Therapy, Vol.8 No.2.

more cases where female children are abandoned when difficulties strike their home. This trend correlates with the thought among the female adolescents that their anxiety about disasters will be resolved through marriage to a good man with whom they can create a peaceful home.

Many of the sandpictures depicted scenes of people and animals living in peaceful coexistence. Often there was a juxtaposition of gods with peaceful families, which may express a belief that life is subject to the gods' will and also serve as a prayer for peace in family and Nature. Overall, the number of cases where a participant created the scene of an earthquake or its aftermath was much lower. In many cases a peaceful scene of Nature, marriage, and well-decorated houses appeared repetitively. This is probably owing to the culture of Nepal - in particular, the Hindu belief that gods are creators of Nature as much as they are destroyers.

\section{Conclusion}

The purpose of this study was to analyze the process of psychological recovery following natural disasters such as earthquakes as well as the archetypal symbolism in the process of sandplay therapy. The study participants were 12 adolescents who had resided for 16 months in a temporary camp for those displaced by the earthquakes in Nepal in 2015. All of them had witnessed the death or injury of family members, relatives or neighbors.

The participants commonly demonstrated the process of sandplay therapy: scenes of archetypal invasion (Attacks by snakes, beasts, aliens, monsters and unidentified assailants), earthquakes or the aftermath of earthquakes (Earthquake, destruction of buildings, volcanic explosions), Helping Forces (Emergence of heroes, police, father or outsiders/Soldiers, weapons, and fighting scenes between soldiers and animals/monsters, and bad people Gods), and reconstruction of homes (Construction of a new and good nation), Recovery of Order (Division, well-compartmented strong houses/Peaceful nature, family and home). The religious and cultural influences on the participants were reflected in their sandpictures and comments that the earthquake was caused by a divine being. Yet at the same time they expressed in archetypal symbols their ability to recover with the help of this divine presence.

This process has also been demonstrated in sandplay therapy with children who 
migrated to North America from tsunami-hit regions of South Asia (Lacroix et al., 2007). Those participants also expressed their ability to recover with the aid of a divine presence, as well as viewing the disaster as the result of this divine presence due to religious and cultural influences. Linking natural disaster to a divine archetype is consistent with Kawai's study of sandplay therapy with survivors of the 2011 earthquake in Japan. Kawai noted that people had two emotions of fascination and fear toward Nature (2015). When a natural disaster occurred, they feared the power of Nature that brought it. Hence the Japanese built hundreds of Shinto shrines on the seashore (Kawai, 2015). At the same time, people were attracted by the power of Nature and thus they constructed temples to venerate it (Kawai, 2015).

This study demonstrates that sandplay therapy is a suitable method of psychotherapeutic intervention in a culture that regards expressing feelings in nonverbal ways as more appropriate than to verbalize them. Furthermore, given that the culture of Nepal is strongly influenced by Hinduism and at the same time it has a patriarchal society, the way in which women and men express themselves is different (Maharatta et al., 2017; Sharma et al., 2010). These differences require further study.

\section{References}

Brody, V. (1997). Dialogue of touch: Developmental play therapy. Lanham, ML: Rowman \& Littlefield Publisher Inc.

Cho, J-H. (2004). Upanishad philosophy and Buddhism. Seoul: Kyunseowon.

Cook, A., Spinazzola, J., Ford, J., Landtree, C., Blaustein, M., \& Cloitre, M., (2005). Complex trauman in children and adolescents. Psychiatric Annals, 35(5), 390-398.

De Vries, A., \& De Vries, A. (2004). Elsevier's dictionary of symbols and imagery (2nd ed.). Oirschot: Elsevier.

Han, H-H. (2010). Hinduism, the views of nature and ecological ethics. Journal of the Korean Society for the Study of Environmental Philosophy, 9, 145-176.

Jang, M. (2017). Destruction and creation in sandplay of earthquake survivors in Nepal. 2017 International Conference of International Society for Sandplay Therapy in Hawaii. 
Journal of Symbols \& Sandplay Therapy, Vol.8 No.2.

Jang, M. (2015). Analytical psychological meaning of masks in the Hahoe Pyolshin Gut Tal (mask) dance and their symbolism in sandplay therapy. Asian Journal of Child Welfare \& Development. 13(2), 99-112.

Jung, C. G. (1984). Menschenbild und Gottesbild. Grundwerk C. G. Jung Bd. 4. Walter-Verlag AG. (Trans. into Korean in 2007 by Jung Institute of Korea)

Jung, C. G. (1990). Archetypes of the collective unconscious. In The archetypes and the collective unconscious (2nd ed.). CW 9i. Bollingen Series XX. Princeton, NJ: Princeton University Press.

Jung, C. G. (1993). Psychology and alchemy. Bollingen Series CW 12. NJ: Princeton University Press.

Kalff, D. M. (2003). Sandplay: A psychotherapeutic approach to the psyche. Cloverdale, CA: Temenos Press. (Original work published in 1980)

Kawai, T. (2015). Big stories and small stories in the psychology relief work after the earthquake disaster: Life and death. In Huskinson, L. \& Stein, M., Analytical psychology in a changing world: The search for Self, identity and community. New York: Routledge.

Kim, S. (2014). Psychology and religion: Focused on the thought of C. G. Jung. Theology and Praxis, 34, 285-318.

Lacroix, L., Rousseau, C., Gauthier, M-F., Singh, A., Giguere, N., \& Lemzoudi, Y. (2007). Immigrant and refugee preschoolers' sandplay representation the tsunami. Arts in Psychotherapy, 34, 99-113. doi:10.1016/j.aip.2006.09.006

Lakoff, G., \& Johnson, M. (1980). Metaphors with live by. Chicago, IL: University of Chicago Press.

Lazarus, P., Jimerson, S., \& Brock, S. (2003). Responding to natural disasters: Helping children and families. Information for school crisis teams. Retrieved July 18, 2016, from http://www. nasponline.org/NEAT/naturaldisaster_teams_ho.pdf.

Lazarus, R. S., \& Folkman, S. (1984). Stress, appraisal, and coping. New York: Springer.

Maharatta, K, Samuel, R., Sharma, P., Dixit, L., \& Shrestha, B. R. (2017). Suicide burden and prevention in Nepal: The need for a national strategy. WHO South-East Asia journal of Public Health, Q(1), 45-49. doi:10.4103/2224-3151.206164 
Markell, M. J. (2002). Sand, water, silence - The embodiment of spirit: Explorations in matter and psyche. London: Jessica Kingsley Pubs.

Malchiodi, C. (2003). Using creative activities as intervention for grieving children in preschool triads. Developmental Psychology, 20, 807-814.

Marteau, T. M., Hollands, G. J., \& Fletcher, P. C. (2012). Changing human behavior to prevent disease: The importance of targeting automatic processes. Science, 337(6101), 1492-1495. doi:10.1126/science.122691

Perry, B. D. (2008). Child maltreatment: The role of abuse and neglect in developmental psychopathology. In T. P. Beauchaine \& S. P. Henchaw (Eds.), Textbook of child and adolescents psychopathology (pp. 93-128). New York: Wiley.

Rhi, B-Y. (2012). Korean shamanism and analytical psychology: Searching for sufferings and healing. Seoul: Hangil-sa.

Salloum, A., \& Lewis, M. L. (2010). An exploratory study of African American parent-child coping strategies post-Hurricane Katrina. Traumatology, 16, 31-41. doi:10.1177/ 1534765609348240

Sara, S. J., \& Bouret, S. (2012). Orienting and reorienting: The locus coeruleus mediates cognition through arousal. Neuron, 76, 130-141. doi:10.1016/j.neuron.2012.09.011

Sharma, P. P., Jha, A. K., Joshi, A., \& Lamsal, R. (2010). Mass hysteria and adolescent girl: An interventional study. Nepal Journal of Obstetrics and Gynaecology, 5(1), 17-20. doi: 10.3126/njog.v5i1.5055

Sharp, D. (1991), C. G. Jung lexicon: A primer of terms and concepts, Toronto: Inter City Books.

Smith, L., Bernal, D. R., Schwartz, B. S., Whitt, C. L., Christman, S. T., Donnelly, S., Wheatley, A., Guillaumen, C., Nicolar, G., Kish, J., \& Kobetz, E. (2014). Coping with vicarious trauma in the aftermath of a natural disaster. Journal of Multicultural Counseling and Development, 42, 2-12. doi:10.1002/j.2161-1912.2014.00040.x

Steinhardt, L. (2000). Foundation and form in Jungian sandplay. London/Philadelphia: Jessica Kingsley.

Steele, W. (2006). When cognitive interventions fail with children of trauma: Memory, learning, and trauma intervention. Retrieved May 24, 2016 from http:/www.tlcinstitue.org/ 
Journal of Symbols \& Sandplay Therapy, Vol.8 No.2.

cognitiveinterventions.html.

Wilson, J. P., \& Lindy, J. (2013). Trauma, culture and metaphor: Pathways of transformation and integration. London \& New York: Routledge.

Received : October 29, 2017

Revised : December 01, 2017

Accepted : December 14, 2017 